\title{
Acute effects of air pollution on respiratory health of 50-70 yr old adults
}

\author{
S.C. van der Zee*, G. Hoek*, M.H. Boezen**, J.P. Schouten**, J.H. van Wijnen ${ }^{+}$, B. Brunekreef*
}

Acute effects of air pollution on respiratory health of 50-70 yr old adults. S.C van der Zee, G. Hoek, M.H. Boezen, J.P. Schouten, J.H. van Wijnen, B. Brunekreef. (C)ERS Journals Ltd 2000.

ABSTRACT: The aim of this study was to investigate the association between daily changes in respiratory health and air pollution in 489 adults, aged 50-70 yrs, with and without chronic respiratory symptoms, living in urban and nonurban areas in the Netherlands.

Subjects were selected from the general population with a screening questionnaire. During three consecutive winters starting in 1992/1993, peak expiratory flow (PEF) and respiratory symptoms were registered in a daily diary. Daily measurements of particles with a 50\% cut-off aerodynamic diameter of $10 \mu \mathrm{m}$ (PM10), black smoke (BS), sulphate, sulphur dioxide $\left(\mathrm{SO}_{2}\right)$ and nitrogen dioxide $\left(\mathrm{NO}_{2}\right)$ were conducted. The difference in PM10, BS and sulphate concentrations between urban and nonurban areas was small, but there was more contrast in the concentrations of $\mathrm{SO}_{2}$ and $\mathrm{NO}_{2}$.

In symptomatic subjects from urban areas, $\mathrm{PM10}$, BS, sulphate and $\mathrm{SO}_{2}$ concentrations were associated with the prevalence of large decrements in morning PEF $(>\mathbf{2 0} \%$ below the median). BS in particular was also associated with upper respiratory symptoms (URS). The magnitude of the effect estimates was in the order of an $80 \%$ increase in PEF decrements and a $20 \%$ increase in URS for a $40 \mu \mathrm{g} \cdot \mathrm{m}^{-3}$ increase of the same day BS concentration. In symptomatic subjects from nonurban areas, no consistent associations between air pollution and health indicators were observed. However, the differences in effect estimates between urban and nonurban symptomatic panels were small and nonsignificant. In nonsymptomatic adults from both areas, no consistent pattern of associations with air pollution was found.

In conclusion, air pollution effects were only found in symptomatic adults in the urban areas.

Eur Respir J 2000; 15: 700-709.

Severe winter air pollution episodes in the past have been associated with serious health effects, such as increased hospital admissions and mortality [1]. Over the last few decades, concentrations of "traditional" winter air pollution components such as sulphur dioxide $\left(\mathrm{SO}_{2}\right)$ and airborne coarse particulates have decreased in the Netherlands and other European countries. This decrease can be ascribed to emission abatement measures and changes in energy production for industrial processes and space heating. Levels of other pollutants such as nitrogen dioxide $\left(\mathrm{NO}_{2}\right)$ and ozone $\left(\mathrm{O}_{3}\right)$ have increased during the same period, largely as a result of an increased intensity of motorized traffic. Motorized traffic also plays an imporant role in the formation of particulate air pollution, both direct and indirect through the formation of secondary aerosols [2]. Recent studies have demonstrated that current levels of particulate air pollution are associated with respiratory morbidity and lung function, even at concentrations well below the 1987 World Health Organization (WHO) Air Quality Guidelines for Europe [3, 4]. Previous studies conducted in the Netherlands have also demonstrated associations between low levels of winter air pollution and respiratory health of children [5-7].
*Environmental and Occupational Health Group, University of Wageningen, Wageningen, The Netherlands. **Dept of Epidemiology and Statistics, University of Groningen, Groningen, The Netherlands. ${ }^{+}$Dept of Environmental Medicine, Municipal Health Service, Amsterdam, The Netherlands.

Correspondence: S.C. van der Zee, Dept of Environmental Sciences, Environmental Health Group, University of Wageningen, PO Box 238, 6700 AE, Wageningen, The Netherlands. Fax: 31317485278

Keywords: Adults

air pollution

chronic respiratory symptoms respiratory health

Received: April 131999

Accepted after revision December 311999

The study was supported by grants from the Netherlands Asthma Fund and the Ministry of the Environment.
These studies have mainly been conducted in nonurban areas. It was not clear to what extent such associations would be different in urban areas where the contribution of local sources to the air pollution mixture is greater than in nonurban areas.

Most time-series studies investigating acute effects of air pollution on lung function and respiratory symptoms have focused on children. The few studies that have been performed in adults have mainly investigated asthma patients [8-11]; one study focused on a random sample of the general population [12]. Previous panel studies in children have demonstrated acute effects of air pollution in, among others, children with mild chronic respiratory symptoms $[5,13,14]$. It is not clear whether adults with mild chronic respiratory symptoms are also susceptible to acute effects of air pollution such as transient changes in lung function and respiratory symptoms. One study reported that pulmonary function of smoking adults with mild to moderate chronic obstructive pulmonary disease was affected by exposure to particles with a 50\% cut-off aerodynamic diameter of $10 \mu \mathrm{m}$ (PM10), but this study was based on only two measurements of pulmonary function per subject [15]. 
Studies investigating effects of air pollution on mortality have suggested that the elderly are a susceptible subgroup [16]. To the authors' knowledge, it has never been investigated whether older adults are also sensitive to acute effects of air pollution on lung function and respiratory symptoms. These considerations led the authors' to perform a large study during three consecutive winters starting in 1992/1993. The study was designed to compare acute health effects of winter air pollution in subjects living in urban and nonurban areas. Selected panels of school children (7-11 yrs) and older adults (50-70 yrs) with and without chronic respiratory symptoms were studied. This paper describes the results for the adult panels. The results for the children are reported elsewhere [17].

\section{Methods}

\section{Study design}

The study was carried out during three consecutive winters starting in 1992/1993. During each winter, panels of adults (50-70 yrs) with and without chronic respiratory symptoms were selected from an urban and a nonurban area. During the first winter the study had a pilot character, and no panels were studied in the nonurban area. The adults were selected from the general population with a screening questionnaire. During study periods which generally lasted for 3 months, daily measurements of peak expiratory flow (PEF) were made, and the occurrence of respiratory symptoms and bronchodilator use was registered in a diary. Air pollution was monitored daily on central sites in each community.

\section{Study population}

The following study areas were chosen: Rotterdam (1992/1993), Amsterdam and Meppel (1993/1994), and Amsterdam and Nunspeet (1994/1995). Figure 1 shows the locations of the areas. Rotterdam is a port and industrial city with $\sim 600,000$ inhabitants. Amsterdam, the nation's capital (720,000 inhabitants), has a relatively small industrial area; local air pollution is caused primarily by emissions from motorized traffic. In addition to local air pollution, transport of air pollution from other parts of the Netherlands and from other European countries contributes to air pollution levels in Dutch cities. Meppel (32,000 inhabitants) and Nunspeet (24,000 inhabitants) are small nonindustrial towns. As the authors wanted to maximize exposure contrasts between urban and nonurban sites, both in Rotterdam and Amsterdam parts of the inner city were selected with a high traffic intensity and a high population density, and no local industrial sources.

A random sample of names and addresses from subjects with Dutch nationality and aged 50-70 yrs was obtained from the respective municipal authorities. Subjects were approached by mail. Screening questionnaires were used to obtain information on chronic respiratory symptoms. The screening questionnaire consisted of selected questions from the questionnaire used in the European Community Respiratory Health Survey [18]. Subjects were considered eligible for the panel with chronic respiratory symptoms

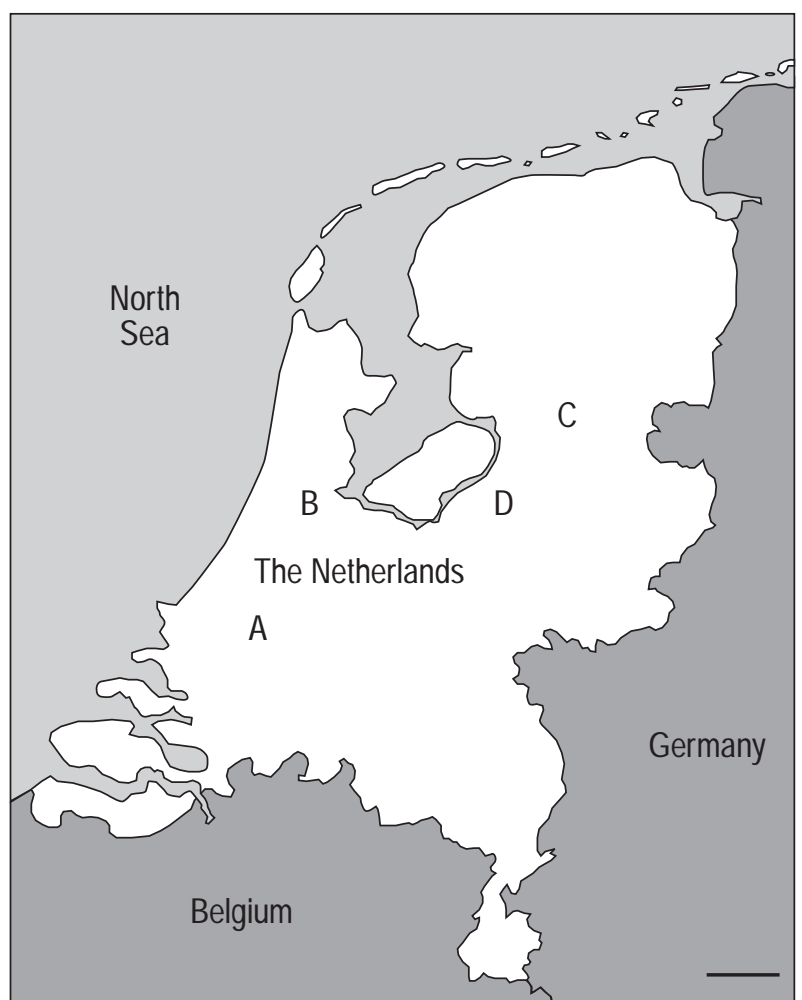

Fig. 1. - Location of urban and nonurban areas during winters in 19921995. A: Rotterdam (urban area 1992/1993); B: Amsterdam (urban area 1993/1994 and 1994/1995); C: Meppel (nonurban area 1993/1994); D: Nunspeet (nonurban area 1994/1995). Scale bar=30 km.

if they reported a positive answer to one or more of six questions about wheeze/asthma (wheeze with shortness of breath; wheeze without a cold; shortness of breath at normal walking pace; need to recover breath while walking at own pace; asthma attacks in last 12 months; current use of asthma medication), or to one or more of five questions about cough/phlegm (last 12 months: daily cough upon rising, or during day/night for 3 months per year; last 12 months: daily production of phlegm upon rising, or during day/night for 3 months per year; 3 weeks of productive cough during last 3 yrs). During the winter of 1994/1995, the selection question of productive cough was omitted as it was felt that it primarily selected subjects with "smokers cough". Subjects without any reported symptoms on the screening questionnaire were considered eligible for the "nonsymptomatic" panels. Only subjects who signed informed consent letters were included in the study. Symptomatic and nonsymptomatic subjects were selected randomly from those who fulfilled the selection criteria. The panel size aimed for was 30 subjects in the pilot-study in 1992/1993, and 75 subjects in each panel in 1993/1994, 60 symptomatic and 40 nonsymptomatic subjects in 1994/1995. The study was approved by the Medical Ethical Committee of the University Hospital Groningen and the Medical Ethical Committee of the Municipal Health Service in Amsterdam.

\section{Exposure assessment}

Detailed information about the measurement sites and methods is given elsewhere [19]. Briefly, 24-h measurements of PM10, black smoke (BS) and fine aerosol 
sulphate, nitrate, ammonium and strong acidity were made at fixed sites in the urban and nonurban areas. Measurements ran from 15:00 h to 15:00 h. The particle measurement sites were chosen such that they were close to the living area of the participating subjects, and not strongly influenced by local sources such as traffic and industry. Measurements of PM10 were made with an instrument described by LIU and PUI [20], equipped with an inlet similar to the Sierra Andersen 241 dichotomous sampler (Graseby Andersen, Atlanta, GA, USA), using Schleicher \& Schuell TE37 teflon filters (Schleicher and Schuell Inc. Keene, NH, USA) (pore size $1 \mu \mathrm{m}$ ). The inlet was compared to the Sierra Andersen inlet in a series of 33 collocated measurements [21]. The estimated regression equation was $6.0+0.90 *$ Sierra-PM10 ( $\mathrm{r}=0.93)$, where Sierra-PM10 is the PM10 concentration measured with the Sierra Andersen sampler [21].

BS was measured using the Organization for Economic and Cooperation and Development (OECD) method, which involves collection of particles on a Whatman 1 paper filter (Whatman Lab. Sales, Hillsboro, OR, USA) using a low volume sampler [22]. Sampling of nitrate, sulphate, ammonium and aerosol acidity was performed with an annular denuder filter pack system. The impactor was designed to remove particles with a $50 \%$ cut off diameter of $2.1 \mathrm{~mm}$ at a flow rate of $10 \mathrm{~L} \cdot \mathrm{min}^{-1}[23]$. The sampling method and the extraction of the filters for the determination of sulphate, nitrate and ammonium is described in detail by HoEK et al. [24].

Information about the ambient concentrations of $\mathrm{SO}_{2}$ and $\mathrm{NO}_{2}$ was obtained from the nearest measurement sites of the National Air Quality Monitoring Network [25]. $\mathrm{SO}_{2}$ and $\mathrm{NO}_{2}$ were measured by continuous monitors based on fluorescence and chemiluminescence respectively [25]. $\mathrm{SO}_{2}$ and $\mathrm{NO}_{2}$ concentrations were transformed into 24-h average concentrations from 15:00 h to $15: 00 \mathrm{~h}$. Minimum temperature between 15:00 $\mathrm{h}$ and 15:00 $\mathrm{h}$ was used in the analysis. Temperature data from the nearest site of the Dutch Royal Meteorological Society were used.

Data on the weekly incidence of influenza-type illnesses were obtained from a sentinel system operated by the Dutch Institute of Primary Health Care. The authors recently documented that these data were associated with the outcome variables measured in the panels [26], for which reason they are included as potential confounders of the association between air pollution and respiratory health in this study.

\section{Health measurements}

During the study period, participants performed PEF measurements twice daily using Mini Wright peak flow meters (Clement Clarke, Essex, UK), once in the morning before breakfast and in the evening before going to bed. Subjects were instructed to perform the PEF measurements before any medication was taken. Every test consisted of three manoeuvres and participants were asked to note all three readings in a diary. The highest of the three PEF readings was used for analysis. The diary was also used to register the occurrence of acute respiratory symptoms and medication use (cough, phlegm, runny/stuffed nose, woken up with breathing problems, shortness of breath, wheeze, $\operatorname{attack}(\mathrm{s})$ of shortness of breath with wheeze and fever).
During the winters of $1993 / 1994$ and $1994 / 1995$, the symptoms, eye irritation and sore throat, were also included. Subjects were instructed to indicate whether the symptoms were absent, slight, or moderate/severe on each day. Medication use was assessed by having the subjects indicate the name of the medication and the number of units taken. The appropriate use of the diary and Mini Wright meter was demonstrated during a home visit.

\section{Data analysis}

The methods of the Pollution Effects on Asthmatic Children in Europe (PEACE) study were used to analyse the association between air pollution and respiratory health $[27,28]$. Here only a brief overview and the deviations are discussed. All panels were analysed separately. Next, combined effect estimates were calculated for symptomatic and nonsymptomatic panels, and for urban and nonurban areas separately.

The symptoms shortness of breath, wheeze and attacks of shortness of breath with wheeze were combined as lower respiratory symptoms (LRS). Runny/stuffed nose and sore throat were combined as upper respiratory symptoms (URS). Only LRS, URS, cough, phlegm and bronchodilator use were analysed. For the analysis of PEF data, the daily prevalence of $10 \%$ and $20 \%$ decrements below the individual median of morning and evening PEF were analysed [29]. The authors preferred this method to the analysis of population mean PEF [27, 28] because it demonstrates better the clinical significance of PEF associations. The explanatory variables were $24 \mathrm{~h}$ average concentration of PM10, $\mathrm{BS}, \mathrm{SO}_{2}, \mathrm{NO}_{2}$ sulphate and nitrate, analysed separately. Current day concentration (lag 0 ), previous day concentration (lag 1), concentration of 2 days before (lag 2) and the average concentration of 0-4 days before ( 5 day mean) were analysed separately.

The association between air pollution and the prevalence of PEF decrements, symptoms and bronchodilator use was evaluated with logistic regression, adjusting for first order autocorrelation. The number of subjects reporting on each day was used as weight. Minimum daily temperature, an indicator variable for day of week (Monday to Friday versus Saturday to Sunday), time trend, and the incidence of influenza and influenza-like illness (ILI) in the general population were included in the model as potential confounders. Time trend was included as a linear, quadratic and cubic term. This was done because in some panels nonlinear time trends were observed in the prevalence of symptoms, medication use and PEF decrements. An exception was made for the 1992/1993 pilot study, in which the study period was so short ( $\sim 6$ weeks) that modelling with three time trends resulted in removal of short term time variations. For this winter only a linear trend was specified. In the confounder model building stage of the analyses different models for time trend were checked without air pollution in the model. The authors have compared models which specified no time trend term, a linear trend term only, two separate linear time trends for different parts of the study period and a linear, quadratic and cubic trend term ("final" model). Judged by the adjusted $\mathrm{R}^{2}$ of the model, the cubic polynomial model was generally the best model. Models which specified no trend term or a linear trend term only had a substantial lower 
adjusted $\mathrm{R}^{2}$. Sensitivity analyses showed that the air pollution effect estimates were similar for the final model and the model with two linear terms (which sometimes had slightly higher adjusted $\mathrm{R}^{2}$ ). Plots of the predicted prevalence were evaluated based on the parametric "final" model and residuals of this model. This showed that the long term trends ( $>14$ days) were predicted well, while the short term variation $(<14$ days) was not removed. Thus it was not necessary to specify even more flexible models for trend such as smooth functions of day of study. The autocorrelation structure was checked by evaluation of the partial autocorrelation function using PROC ARIMA in SAS (SAS Institute Inc. Cary, NC, USA). This showed that a first order autoregressive parameter term removed the autocorrelation sufficiently.

The incidence of ILI, registered by the Dutch network of sentinel practices, was included in the model with two variables representing, respectively, the mean incidences of 0-6 days earlier and 7-13 days earlier [26]. ILI was an addition to the confounders used in the PEACE study [27, 28].

Combined effect estimates were calculated for symptomatic and nonsymptomatic panels, and for urban and nonurban areas separately, using the regression slopes from the panel-specific logistic regression models for the three winters.

Combined effect estimates were calculated as the weighted mean of the panel-specific slopes, with the weights being the inverse of the panel-specific variances of the slopes. The standard error of the combined slope was calculated as the inverse of the square root of the sum of weights.
To test whether the association between air pollution and respiratory health differed significantly between urban and nonurban areas, a weighted linear regression was performed with the panel-specific regression slopes as the dependent variable and an indicator variable for area (urban versus nonurban) as the independent variable. The inverse of the panel-specific variances of the slopes were used as weights.

All statistical analyses were conducted using SAS (SAS Institute Inc., Cary, NC, USA) [30].

\section{Results}

From the 11,519 screening questionnaires handed out during the three winters, 4,464 (39\%) were returned. The response was similar in the urban and nonurban areas $(38 \%$ and $40 \%$, respectively). Of the 4,464 returned questionnaires, 751 subjects (17\%) were eligible and willing to participate in the symptomatic panels, whereas 601 subjects $(13 \%)$ were eligible and willing to participate in the nonsymptomatic panels. From the 326 symptomatic and 274 nonsymptomatic subjects that were enrolled, respectively, 266 and 223 were included in the final analysis, the remainder generally having too few observations.

In table 1 some characteristics of the panels are shown. Mean age was $\sim 60$ yrs in all panels. The fraction of subjects exposed to environmental tobacco smoke was highest in the symptomatic panel from the urban areas and lowest in the nonsymptomatic panel from the nonurban areas. Recent shortness of breath and wheeze,

Table 1. - Characteristics of the panels, three winters combined

\begin{tabular}{|c|c|c|c|c|}
\hline & $\begin{array}{l}\text { Symptomatic, } \\
\text { urban area }\end{array}$ & $\begin{array}{l}\text { Symptomatic, } \\
\text { nonurban area }\end{array}$ & $\begin{array}{c}\text { Nonsymptomatic, } \\
\text { urban area }\end{array}$ & $\begin{array}{c}\text { Nonsymptomatic, } \\
\text { nonurban area }\end{array}$ \\
\hline Original sample size & 173 & 153 & 140 & 134 \\
\hline Final sample size* & 138 & 128 & 111 & 112 \\
\hline Winter 1992/1993 & 21 & - & 15 & - \\
\hline Winter $1993 / 1994$ & 63 & 70 & 56 & 73 \\
\hline Winter $1994 / 1995$ & 54 & 58 & 40 & 39 \\
\hline Sex $\%$ males & 50 & 48 & 40 & 46 \\
\hline Mean age SD & $59.1(6.1)$ & $61.0(6.2)$ & $58.9(5.6)$ & $60.1(6.3)$ \\
\hline Exposed to ETS in the home $\% * *$ & 46 & 35 & 37 & 16 \\
\hline \multicolumn{5}{|c|}{$\begin{array}{l}\text { Screening prevalence of symptoms and } \\
\text { medication use } \% \text { in final sample }\end{array}$} \\
\hline Recent wheeze/shortness of breath & 43 & 44 & 0 & 0 \\
\hline Chronic cough & 38 & 31 & 0 & 0 \\
\hline Chronic phlegm & 40 & 33 & 0 & 0 \\
\hline Recent asthma attacks & 8 & 12 & 0 & 0 \\
\hline Current use of asthma medication & 17 & 25 & 0 & 0 \\
\hline \multicolumn{5}{|c|}{$\begin{array}{l}\text { Mean daily prevalence of symptoms, medication } \\
\text { use and PEF decrements, and mean PEF \%*, }\end{array}$} \\
\hline Lower respiratory symptoms & 20 & 27 & 1.8 & 1.8 \\
\hline Upper respiratory symptoms & 35 & 26 & 13 & 8.6 \\
\hline Cough & 36 & 31 & 8.6 & 7.8 \\
\hline Phlegm & 34 & 35 & 7.4 & 3.9 \\
\hline Bronchodilator use & 7.7 & 17 & - & - \\
\hline$>10 \%$ decrements in morning PEF & 6.8 & 5.7 & 6.0 & 2.2 \\
\hline$>20 \%$ decrements in morning PEF & 1.5 & 0.8 & 0.2 & 0.4 \\
\hline Mean morning PEF $\mathrm{L} \cdot \mathrm{min}^{-1}$ & 439 & 425 & 487 & 507 \\
\hline
\end{tabular}

ETS: environmental tobacco smoke; PEF: peak expiratory flow. *: smaller than original sample size because subjects with $>40 \%$ missing diary information were excluded; **: positive answer to the question: "Does anyone in your household smoke inside the home on a regular basis?"; : pooled prevalences and PEF were calculated as the mean of the panel-specific prevalences and PEF, weighted for the number of person-days that each panel contributed. 
Table 2. - Median and maximum of $24 \mathrm{~h}$ average air pollution concentrations $\left(\mu \mathrm{g} \cdot \mathrm{m}^{-3}\right)$, and median and range of temperature $\left(\mathrm{T} ;{ }^{\circ} \mathrm{C}\right)$, and incidence of influenza-like illness (ILI; incidence per 10,000 subjects per week), observed during the study periods in urban and nonurban areas

\begin{tabular}{|c|c|c|c|c|c|c|c|c|c|}
\hline & Study period ${ }^{\#}$ & $\begin{array}{l}\text { No. } \\
\text { days }\end{array}$ & PM10 & $\begin{array}{l}\text { Black } \\
\text { smoke }\end{array}$ & Sulphate & $\begin{array}{l}\text { Sulphur } \\
\text { dioxide }\end{array}$ & $\begin{array}{l}\text { Nitrogen } \\
\text { dioxide }\end{array}$ & $\mathrm{T}^{*}$ & ILI0-6** \\
\hline \\
\hline nonurban & - & - & - & - & - & - & - & - & - \\
\hline 1993/1994 & & & & & & & & & \\
\hline urban & 3/11/93-6/3/94 & 124 & $37(123)$ & $12(65)$ & $2.7(24)$ & $11(34)$ & $48(76)$ & $2.7(-8.1-10.0)$ & $6(0-70)$ \\
\hline $\begin{array}{c}\text { nonurban } \\
1994 / 1995\end{array}$ & 20/11/93-6/3/94 & 107 & $34(242)$ & $10(58)$ & $2.7(23)$ & $5.0(42)$ & $25(54)$ & $1.2(-10.9-9.3)$ & $6(0-39)$ \\
\hline urban & 24/11/94-5/3/95 & 102 & $29(90)$ & $6.9(28)$ & $1.6(10)$ & $6.0(24)$ & $47(82)$ & $3.8(-5.0-11.3)$ & $4(0-10)$ \\
\hline nonurban & 23/11/94-5/3/95 & 103 & $24(97)$ & $5.8(43)$ & $.1 .9(18)$ & $3.6(17)$ & $22(57)$ & $3.1(-11.1-11.3)$ & $8(2-13)$ \\
\hline
\end{tabular}

PM10: particles with a $50 \%$ cut-off aerodynamic diameter of $10 \mu \mathrm{m}$. ${ }^{\#}$ : given as days, months and years; *: minimum daily temperature; **: mean of incidence of influenza-like illness in the previous week.

chronic cough and chronic phlegm were the symptoms with the highest prevalences in the symptomatic panels. Symptomatic panels had a higher prevalence of acute respiratory symptoms than nonsymptomatic panels. The prevalence of $>10 \%$ decrements in morning PEF was on average $6.3 \%$ in the symptomatic panels and $4.1 \%$ in the nonsymptomatic panels, but was substantially higher for nonsymptomatic panels from the urban area $(6.0 \%)$ than for non-symptomatic panels in the nonurban area $(2.2 \%)$. In the nonsymptomatic panels, bronchodilator use was not reported, whereas LRS were rarely reported. In the symptomatic panels, bronchodilator use was higher in the nonurban area $(17 \%)$ than in the urban area $(8 \%)$.

For both symptomatic and nonsymptomatic panels, time trends occurred in the prevalence of acute respiratory symptoms and decrements in PEF that were not always linear. Therefore, time trend was adjusted for by specifying a third order polynomial of day of study.

In table 2 the results of the air pollution measurements are presented. The median concentrations of PM10 and BS were only slightly higher in the urban areas than in the nonurban areas. There was more contrast in the concentration of the gaseous pollutants, $\mathrm{SO}_{2}$ and $\mathrm{NO}_{2}$. The median concentration of sulphate was slightly lower in the urban than in the nonurban areas. Concentrations of aerosol acidity were very low during the three winters (not shown). Only a few concentrations were above the detection limit of $0.10 \mu \mathrm{g} \cdot \mathrm{m}^{-3}$ and therefore, concentrations of aerosol acidity were not used in further analyses.
Table 3 presents the range of the Spearman correlations between the various air pollutants and potential confounding variables, calculated separately for the urban and nonurban areas during the three winters. A high correlation was observed between PM10 and the other indicators for particulate air pollution BS and sulphate. The correlations between other air pollutants, and between air pollutants and temperature were moderately high. Low correlations were observed between air pollutants and the potential confounders day of study and ILI incidence. The correlation between the concentrations measured for the same component in the urban and the nonurban areas was for PM10, BS and sulphate $>0.7$ for all winters. For $\mathrm{SO}_{2}$ and $\mathrm{NO}_{2}$, the correlations were $>0.6$, except for $\mathrm{SO}_{2}$ in the third winter $(\mathrm{R}=0.31)$ when $\mathrm{SO}_{2}$ levels were extremely low.

Both for symptomatic and nonsymptomatic subjects, the association between nitrate concentration and respiratory health was also analysed. However, due to the high correlation with sulphate $(\mathrm{R}=0.75-0.87)$ the effect estimates for nitrate were nearly identical to those for sulphate, and therefore, the results are not presented. Sulphate was chosen to serve as an indicator for secondary aerosols, representing particles that mainly result from long distance transport in the Netherlands.

Table 4 presents the associations between air pollution and the prevalence of $>10 \%$ and $>20 \%$ decrements in morning PEF, respiratory symptoms and bronchodilator use in symptomatic subjects. It shows that, in the

Table 3. - Range of Spearman correlation coefficients between $24 \mathrm{~h}$ average concentration of air pollutants and potential confounding variables, calculated separately for three winters in urban and nonurban areas $(n=5)$

\begin{tabular}{lccccccccc}
\hline & PM10 & $\begin{array}{c}\text { Black } \\
\text { smoke }\end{array}$ & Sulphate & $\begin{array}{c}\text { Sulphur } \\
\text { dioxide }\end{array}$ & $\begin{array}{c}\text { Nitrogen } \\
\text { dioxide }\end{array}$ & Temperature & $\begin{array}{c}\text { Day of } \\
\text { study }\end{array}$ & ILI0-6* & ILI7-13** \\
\hline PM10 & 1 & $0.45-0.84$ & $0.54-0.78$ & $0.31-0.78$ & $0.16-0.72$ & $-0.57-0.19$ & $-0.31-0.30$ & $-0.37-0.51$ & $-0.49-0.05$ \\
Black smoke & - & 1 & $0.52-0.84$ & $0.21-0.75$ & $0.54-0.88$ & $-0.64-0.03$ & $-0.43-0.17$ & $-0.31-0.43$ & $-0.36-0.04$ \\
Sulphate & - & - & 1 & $0.29-0.69$ & $0.25-0.65$ & $-0.58-0.41$ & $-0.26-0.08$ & $-0.25-0.24$ & $-0.32-0.02$ \\
Sulphur dioxide & - & - & - & 1 & $0.47-0.51$ & $-0.53-0.23$ & $-0.53-0.25$ & $-0.21-0.43$ & $-0.37-0.50$ \\
Nitrogen dioxide & - & - & - & - & 1 & $-0.53-0.08$ & $-0.51-0.20$ & $-0.23-0.40$ & $-0.27-0.20$ \\
Temperature & - & - & - & - & - & 1 & $-0.14-0.25$ & $-0.25-0.16$ & $-0.25-0.18$ \\
Day of study & - & - & - & - & - & - & 1 & $-0.86-0.07$ & $-0.81-0.21$ \\
ILI0-6* & - & - & - & - & - & - & - & 1 & $0.16-0.76$ \\
ILI7-13** & - & - & - & - & - & - & - & - & 1 \\
\hline
\end{tabular}

PM10: particles with a 50\% cut-off aerodynamic diameter of $10 \mu \mathrm{m} . *$ : mean of incidence of influenza-like illness (ILI) in the previous week (mean of $0-6$ days before); **: mean of incidence of ILI in week before previous week (mean of $7-13$ days before); ${ }^{\#}$ : daily minimum temperature. 
Table 4. - Odds ratios (OR) with $95 \%$ confidence intervals for the association between air pollution and the prevalence of $>10 \%$ decrements, acute respiratory and bronchodilator use in symptomatic adults, calculated from combined effect estimates

\begin{tabular}{|c|c|c|c|c|c|c|c|c|c|c|}
\hline & \multicolumn{5}{|c|}{ Urban areas } & \multicolumn{5}{|c|}{ Nonurban areas } \\
\hline & $\begin{array}{l}>10 \% \text { in } \\
\text { PEFmo }\end{array}$ & $\begin{array}{l}>20 \% \text { in } \\
\text { PEFmo }\end{array}$ & LRS & URS & & $\begin{array}{l}-10 \% \text { in } \\
\text { PEFmo }\end{array}$ & $\begin{array}{l}>20 \% \text { in } \\
\text { PEFmo }\end{array}$ & LRS & URS & Broncho \\
\hline \multicolumn{11}{|l|}{ PM10 } \\
\hline & $\begin{array}{c}0.84 \\
(0.55-1.28)\end{array}$ & $\begin{array}{c}2.08 \\
.05-4.12)^{*}\end{array}$ & $\begin{array}{c}0.97 \\
(0.80-1.17)\end{array}$ & $\begin{array}{c}1.09 \\
(0.93-1.29)\end{array}$ & $\begin{array}{c}0.98 \\
(0.82-1.17)\end{array}$ & $\begin{array}{c}0.99 \\
(0.67-1.45)\end{array}$ & $\begin{array}{c}1.11 \\
(0.43-2.81)\end{array}$ & $\begin{array}{c}1.02 \\
(0.91-1.14)\end{array}$ & $\begin{array}{c}0.99 \\
(0.85-1.14)\end{array}$ & $\begin{array}{c}0.98 \\
(0.90-1.06)\end{array}$ \\
\hline Lag 1 & $\begin{array}{c}0.93 \\
(0.63-1.37)\end{array}$ & $\begin{array}{c}1.49 \\
(0.80-2.77)\end{array}$ & $\begin{array}{c}0.97 \\
(0.81-1.16)\end{array}$ & $\begin{array}{c}1.12 \\
(0.96-1.32)\end{array}$ & $\begin{array}{c}0.97 \\
(0.82-1.15)\end{array}$ & $\begin{array}{c}0.98 \\
(0.70-1.39)\end{array}$ & $\begin{array}{c}1.36 \\
(0.62-2.97)\end{array}$ & $\begin{array}{c}1.05 \\
(0.95-1.16)\end{array}$ & $\begin{array}{c}1.13 \\
(0.99-1.28)\end{array}$ & $\begin{array}{c}1.05 \\
(0.97-1.13)\end{array}$ \\
\hline Lag 2 & $\begin{array}{c}0.69 \\
(0.47-1.00)^{\#}\end{array}$ & $\begin{array}{c}1.31 \\
(0.69-2.51)\end{array}$ & $\begin{array}{c}1.02 \\
(0.86-1.22)\end{array}$ & $\begin{array}{c}1.09 \\
(0.93-1.27)\end{array}$ & $\begin{array}{c}0.93 \\
(0.79-1.10)\end{array}$ & $\begin{array}{c}1.10 \\
(0.81-1.49)^{\#}\end{array}$ & $\begin{array}{c}0.72 \\
(0.28-1.84)\end{array}$ & $\begin{array}{c}0.95 \\
(0.86-1.06)\end{array}$ & $\begin{array}{c}1.04 \\
(0.92-1.19)\end{array}$ & $\begin{array}{c}1.00 \\
(0.93-1.08)\end{array}$ \\
\hline $\begin{array}{l}5 \text { day } \\
\text { mean }\end{array}$ & $\begin{array}{c}0.62 \\
(0.32-1.21)\end{array}$ & $\begin{array}{r}1.3 \\
(0.41-\end{array}$ & $\begin{array}{c}0.91 \\
(0.67-1.24)\end{array}$ & $\begin{array}{r}1.2 \\
(1.01-\end{array}$ & $\begin{array}{r}0.7 \\
(0.53\end{array}$ & $\begin{array}{c}1.07 \\
(0.63-1.81)\end{array}$ & $\begin{array}{c}0.69 \\
(0.16-2.94)\end{array}$ & $\begin{array}{c}0.99 \\
(0.82-1.18)\end{array}$ & $\begin{array}{c}1.27 \\
(0.99-1.62)\end{array}$ & $\begin{array}{r}1 . \\
(0.94\end{array}$ \\
\hline \multicolumn{11}{|c|}{ Black smoke } \\
\hline Lag 0 & $\begin{array}{c}1.10 \\
(0.79-1.55)\end{array}$ & $\begin{array}{r}1 . \\
(1.05-\end{array}$ & $\begin{array}{c}0.96 \\
(0.80-1.15)\end{array}$ & $\begin{array}{c}1.18 \\
(1.01-1.38)^{*}, \#\end{array}$ & $\begin{array}{c}0.99 \\
(0.84-1.15)\end{array}$ & $\begin{array}{c}1.10 \\
(0.73-1.68)\end{array}$ & $\begin{array}{c}2.77 \\
(0.89-8.60)\end{array}$ & $\begin{array}{c}1.07 \\
(0.93-1.22)\end{array}$ & $\begin{array}{c}0.96 \\
(0.82-1.12)^{\#}\end{array}$ & 4 $\begin{array}{c}0.96 \\
(0.87-1.07)\end{array}$ \\
\hline Lag 1 & $\begin{array}{r}1.4 \\
(1.05-1\end{array}$ & $\begin{array}{r}1.9 \\
(1.22-3\end{array}$ & $\begin{array}{c}0.95 \\
(0.81-1.11)\end{array}$ & $\begin{array}{r}1.2 \\
(1.12-1\end{array}$ & $\begin{array}{r}1.0 \\
(0.87-\end{array}$ & $\begin{array}{r}0.9 \\
(0.67-\end{array}$ & $\begin{array}{c}1.09 \\
(0.47-2.53)\end{array}$ & $\begin{array}{c}1.09 \\
(0.97-1.22)\end{array}$ & $\begin{array}{c}1.08 \\
(0.95-1.23)^{\#}\end{array}$ & ( 1.95 \\
\hline Lag 2 & $\begin{array}{c}0.93 \\
(0.69-1.25)\end{array}$ & $\begin{array}{c}1.27 \\
(0.78-2.06)\end{array}$ & $\begin{array}{c}0.99 \\
(0.85-1.16)\end{array}$ & $\begin{array}{c}0.97 \\
(0.94-112)\end{array}$ & $\begin{array}{r}0.8 \\
(0.77-\end{array}$ & $\begin{array}{c}1.07 \\
(0.77-1.47)\end{array}$ & $\begin{array}{c}0.84 \\
(0.34-2.08)\end{array}$ & $\begin{array}{c}0.99 \\
0.99\end{array}$ & $\begin{array}{r}0.9 \\
(0.87-\end{array}$ & $\begin{array}{r}1 . \\
(0.93-\end{array}$ \\
\hline $\begin{array}{l}5 \text { day } \\
\text { mean }\end{array}$ & $\begin{array}{c}1.50 \\
(0.94-2.40)\end{array}$ & $\begin{array}{c}4.24 \\
(2.46-7.29)^{*}\end{array}$ & $\begin{array}{c}0.96 \\
(0.75-1.24)\end{array}$ & $\begin{array}{r}1.5 \\
(1.17-1\end{array}$ & $\begin{array}{c}0.78 \\
(0.59-1.03)\end{array}$ & $\begin{array}{c}1.09 \\
(0.60-1.99)\end{array}$ & 1.31 & $\begin{array}{c}1.00 \\
(0.81-1.22)\end{array}$ & $\begin{array}{r}1.1 \\
(0.86-\end{array}$ & $\begin{array}{l}5 \\
1.26)\end{array}$ \\
\hline Lag 0 & $\begin{array}{c}0.90 \\
(0.64-1.25)\end{array}$ & $\begin{array}{c}1.79 \\
.00-3.20)^{*}\end{array}$ & $\begin{array}{c}0.93 \\
(0.79-1.11)\end{array}$ & 1.08 & $\begin{array}{c}0.99 \\
0.85-1.15)\end{array}$ & $\begin{array}{c}1.16 \\
.80-1.68)\end{array}$ & $\begin{array}{c}0.79 \\
(0.29-2.1\end{array}$ & 0.99 & $\begin{array}{c}0.92 \\
(0.79-1.0\end{array}$ & $\begin{array}{c}1.04 \\
(0.94-1.15)\end{array}$ \\
\hline Lag 1 & $\begin{array}{r}1.1 \\
(0.82-\end{array}$ & 1.6 & $\begin{array}{r}1.0 \\
(0.85-\end{array}$ & $\begin{array}{r}1 . \\
(0.96\end{array}$ & $\begin{array}{r}0 . \\
(0.86\end{array}$ & $\begin{array}{r}1 .( \\
(0.74\end{array}$ & $\begin{array}{r}1 . \\
(0.60-\end{array}$ & $\begin{array}{l}5 \\
1.18)\end{array}$ & $\begin{array}{r}1.0 \\
(0.89\end{array}$ & $\begin{array}{r}1 .( \\
(0.94\end{array}$ \\
\hline Lag 2 & $\begin{array}{c}0.83 \\
(0.60-1.15)\end{array}$ & 1.39 & 1.02 & 0.99 & 0.97 & $\begin{array}{c}0.95 \\
(0.68-1.31)\end{array}$ & $\begin{array}{c}1.51 \\
(0.76-2.99)\end{array}$ & 0.97 & 1.09 & $\begin{array}{r}1 . C \\
(0.93-\end{array}$ \\
\hline & $\begin{array}{r}1.38 \\
(0.76-2 \\
\text { dioxide }\end{array}$ & $\begin{array}{r}3.5 \\
(1.02-1\end{array}$ & $\begin{array}{r}0.94 \\
(0.67-1 .\end{array}$ & $\begin{array}{c}1.46 \\
(1.06-2.01)^{*}\end{array}$ & $\begin{array}{c}0.93 \\
(0.67-1.30)\end{array}$ & $\begin{array}{c}1.31 \\
(0.69-2.46)\end{array}$ & $\begin{array}{c}2.40 \\
(0.75-7.69)\end{array}$ & $\begin{array}{c}0.94 \\
(0.77-1.14)\end{array}$ & $\begin{array}{c}1.23 \\
(0.91-1.6\end{array}$ & $\begin{array}{c}1.07 \\
(0.89-1.29)\end{array}$ \\
\hline Lag 0 & $\begin{array}{c}0.86 \\
(0.60-1.2\end{array}$ & 6 & $\begin{array}{c}1.01 \\
(0.84-1.20\end{array}$ & $\begin{array}{c}1.15 \\
(0.97-1.37)\end{array}$ & $\begin{array}{c}1.09 \\
(0.93-1.28)\end{array}$ & $\begin{array}{c}0.79 \\
(0.48-1.29\end{array}$ & $\begin{array}{r}0.7 \\
(0.22-2\end{array}$ & $\begin{array}{c}1.11 \\
(0.94-1.3\end{array}$ & 0.97 & $\begin{array}{c}1.04 \\
(0.91-1.1\end{array}$ \\
\hline Lag 1 & $\begin{array}{c}0.97 \\
(0.68-1.39)\end{array}$ & 1.98 & $\begin{array}{c}0.97 \\
(0.82-1.16)\end{array}$ & 1.06 & $\begin{array}{c}1.05 \\
(0.89-1.24)\end{array}$ & $\begin{array}{c}1.08 \\
(0.68-1.72)\end{array}$ & $\begin{array}{c}0.71 \\
(0.13-4.02)\end{array}$ & $\begin{array}{c}1.04 \\
(0.88-1.22)\end{array}$ & $\begin{array}{c}1.20 \\
(0.98-1.47)\end{array}$ & $\begin{array}{c}1.08 \\
(0.95-1.22)\end{array}$ \\
\hline $\operatorname{Lag} 2$ & $\begin{array}{c}0.87 \\
(0.63-1.20)\end{array}$ & 1.16 & $\begin{array}{c}0.94 \\
(0.80-1.10)\end{array}$ & 0.97 & $\begin{array}{c}0.85 \\
(0.72-0.99)^{*}\end{array}$ & $\begin{array}{c}0.84 \\
(0.38-1.86)\end{array}$ & $\begin{array}{c}1.23 \\
(0.16-9.45)\end{array}$ & $\begin{array}{c}0.92 \\
(080-107)\end{array}$ & 0.99 & 1.02 \\
\hline $\begin{array}{r}5 \text { day } \\
\text { meal }\end{array}$ & $\begin{array}{c}1.06 \\
(0.57-1.98)\end{array}$ & 1.76 & $\begin{array}{c}0.71 \\
(0.53-0.95)^{*}\end{array}$ & $\begin{array}{c}1.27 \\
(0.91-1.76)\end{array}$ & $\begin{array}{c}0.91 \\
(0.65-1.25)\end{array}$ & $\begin{array}{c}0.82 \\
(0.37-1.82)\end{array}$ & $\begin{array}{c}0.64 \\
(0.08-5.40)\end{array}$ & $\begin{array}{c}1.01 \\
(0.77-1.32)\end{array}$ & $\begin{array}{c}1.26 \\
(0.86-1.83)\end{array}$ & $\begin{array}{c}1.14 \\
(0.91-1.41)\end{array}$ \\
\hline & dioxide & & & & & & & & & \\
\hline $\operatorname{Lag} 0$ & $\begin{array}{c}0.98 \\
(0.78-1.22)\end{array}$ & $.59-1.57)$ & $\begin{array}{c}0.96 \\
.86-1.07)\end{array}$ & $\begin{array}{c}1.11 \\
(1.01-1.23)^{*}\end{array}$ & $\begin{array}{c}1.02 \\
(0.93-1.12)\end{array}$ & $\begin{array}{c}1.21 \\
(0.97-1.53)\end{array}$ & $\begin{array}{c}2.65 \\
(1.50-4.66)^{*}\end{array}$ & * $\begin{array}{c}1.00 \\
(0.93-1.09)\end{array}$ & $\begin{array}{c}1.04 \\
(0.95-1.14)\end{array}$ & $\begin{array}{c}1.01 \\
(0.95-1.07)\end{array}$ \\
\hline Lag 1 & $\begin{array}{c}1.19 \\
(0.96-1.46)^{\#}\end{array}$ & $\begin{array}{c}1.18 \\
(0.77-1.82)\end{array}$ & $\begin{array}{c}0.92 \\
(0.83-1.01)\end{array}$ & $\begin{array}{c}1.06 \\
(0.97-1.15)\end{array}$ & 0.98 & 0.98 & $\begin{array}{c}0.97 \\
(0.58-1.63)\end{array}$ & 1.00 & 1.06 & $\begin{array}{c}0.96 \\
(0.90-1.02)\end{array}$ \\
\hline Lag 2 & $\begin{array}{c}0.97 \\
(0.79-1.21)\end{array}$ & $\begin{array}{c}0.81 \\
(0.53-1.24)\end{array}$ & $\begin{array}{c}0.96 \\
(0.87-1.06)\end{array}$ & $\begin{array}{c}0.96 \\
(0.88-1.04)\end{array}$ & $\begin{array}{c}0.96 \\
(0.88-1.04)\end{array}$ & $\begin{array}{c}0.97 \\
(0.78-1.20)\end{array}$ & $\begin{array}{c}0.92 \\
(0.58-1.46)\end{array}$ & $\begin{array}{c}0.99 \\
(0.92-1.07)\end{array}$ & $\begin{array}{c}1.00 \\
(0.91-1.10)\end{array}$ & $\begin{array}{c}1.02 \\
(0.96-1.08)\end{array}$ \\
\hline $\begin{array}{l}5 \text { day } \\
\text { mean }\end{array}$ & $\begin{array}{c}0.90 \\
(0.58-1.41)\end{array}$ & $\begin{array}{c}0.24 \\
(0.08-0.74)^{*}\end{array}$ & $\begin{array}{c}0.74 \\
(0.59-0.95)^{*}\end{array}$ & $\begin{array}{c}0.97 \\
(0.75-1.25)\end{array}$ & $\begin{array}{c}0.85 \\
(0.67-1.08)\end{array}$ & $\begin{array}{c}0.92 \\
(0.61-1.40)\end{array}$ & $\begin{array}{c}1.18 \\
(0.54-2.56)\end{array}$ & $\begin{array}{c}0.92 \\
(0.80-1.06)\end{array}$ & $\begin{array}{c}1.09 \\
(0.89-1.33)\end{array}$ & $\begin{array}{c}0.95 \\
(0.83-10.8)\end{array}$ \\
\hline
\end{tabular}

OR for an increase of $100 \mu \mathrm{g} \cdot \mathrm{m}^{-3}$ in particles with a $50 \%$ cut-off aerodynamic diameter of $10 \mu \mathrm{m}(\mathrm{PM} 10), 40 \mu \mathrm{g} \cdot \mathrm{m}^{-3}$ for black smoke, sulphur dioxide, nitrogen dioxide and $15 \mu \mathrm{g} \cdot \mathrm{m}^{-3}$ for sulphate. *: OR significantly different from $1(\mathrm{p}<0.05)$; : difference in OR between urban and nonurban areas statistically significant $(\mathrm{p}<0.05)$. $>10 \%$ PEFmo: $>10 \%$ decrements in morning peak expiratory flow; $>20 \%$ PEFmo: $>20 \%$ decrements in morning peak expiratory flow; LRS: lower respiratory symptoms; URS: upper respiratory symptoms; broncho: bronchodilator use; Lag 0: current day concentration; Lag 1: previous day concentration; Lag 2: concentration of two days before; 5 day mean: mean concentration of current day and 4 previous days.

urban areas, consistently positive associations were found between the prevalence of $>20 \%$ decrements in morning $\mathrm{PEF}$ and the concentration of PM10, BS, sulphate and $\mathrm{SO}_{2}$, with many associations reaching statistical significance. However, no associations were observed with the prevalence of $>10 \%$ decrements in morning PEF, and with the prevalence of both $>10 \%$ and $>20 \%$ in evening PEF (not shown). Only for BS was the association more consistent across the different PEF variables. For previous day BS (borderline) significant associations were found for all PEF variables. For the $10 \%$ and $20 \%$ evening PEF decre- ments odds ratios (OR) were $1.32(0.98-1.77)$ and 4.24 (2.47-7.29), respectively. In the urban areas there was also a tendency towards a positive association between the prevalence of URS and indicators for particulate air pollution, especially BS. No consistent associations were observed between air pollution and the prevalence of LRS and bronchodilator use. With phlegm and cough no associations were observed either (not shown).

In the symptomatic panels in the nonurban areas no consistent associations were observed between air pollution and respiratory health (table 4). However, especially 
for and sulphate effect estimates for the $>20 \%$ decrements in morning PEF were similar to those of the urban area. The vast majority (96 out of 100) of the evaluated differences in effect estimates between urban and nonurban were statistically nonsignificant.

The associations between air pollution and respiratory health in nonsymptomatic subjects are presented in table 5 . It shows that in the urban areas there was a tendency towards a positive association between sulphate and the prevalence of $>10 \%$ decrements in morning PEF. This association was not found in the nonurban areas. No consistent associations between other respiratory health indicators and air pollution were observed in nonsymptomatic subjects from the urban and the nonurban areas. The prevalence of $>20 \%$ decrements in PEF was so low in the nonsymptomatic panels that it could not be analysed.

\section{Discussion}

In this study, it has been found that in symptomatic adults living in urban areas the daily prevalence of $>20 \%$ decrements in morning PEF had a positive association with $\mathrm{SO}_{2}$ and indicators of particulate air pollution, especially BS. The prevalence of URS was also positively associated with BS and, to a lesser extent, with PM10 and sulphate. No associations were observed between air pollution and the prevalence of other respiratory health indicators, including bronchodilator use, LRS, $>10 \%$ decrements in morning PEF and $>10 \%$ and $>20 \%$ decrements in evening
PEF. $\mathrm{NO}_{2}$ was not related to any of the health end-points. In symptomatic adults living in nonurban areas, no significant and consistent associations between air pollution concentrations and indicators of respiratory health were observed. However, the differences in effect estimates between urban and nonurban were generally small and nonsignificant. In nonsymptomatic adults, no consistent associations were observed at all.

No consistent pattern of associations with air pollution was found for most of the health end-points that were studied. However, for $>20 \%$ morning PEF decrements, consistent associations were found in the symptomatic urban panel. The authors do not believe that these associations represent chance findings resulting from the large number of evaluated associations. The consistent pattern of associations with the different evaluated lags supports this. There was, however, no association with $>10 \%$ PEF morning decrements and both evening PEF variables, with the exception of BS. An explanation might be that the prevalence of the $>10 \%$ and $>20 \%$ decrements was very different ( 6.8 versus $1.5 \%$ in the urban areas, 5.7 versus $0.8 \%$ in the nonurban areas). Because the prevalence of $>20 \%$ decrements was so much lower, a change in this prevalence associated with increased air pollution exposure will not have much impact on the prevalence of $>10 \%$ decrements. Apparently there was a small subgroup experiencing fairly large PEF decrements when air pollution was high, without the air pollution having much effect on PEF of the other panel members.

Table 5. - Odds ratios (OR) with $95 \%$ confirdence intervals for the association between air pollution and the prevalence of $>10 \%$ decrements and acute respiratory symptoms in nonsymptomatic adults, calculated from combined effect estimates

\begin{tabular}{|c|c|c|c|c|}
\hline & \multicolumn{2}{|c|}{ Urban areas } & \multicolumn{2}{|c|}{ Nonurban areas } \\
\hline & $>10 \%$ in PEFmo & URS & $>10 \%$ in PEFmo & URS \\
\hline \multicolumn{5}{|l|}{ PM10 } \\
\hline Lag 0 & $1.14(0.59-2.19)$ & $1.00(0.73-1.37)$ & $0.30(0.11-0.86)^{*}$ & $0.98(0.76-1.26)$ \\
\hline Lag 1 & $2.03(1.16-3.56)^{*}$ & $1.22(0.92-1.61)$ & $1.28(0.63-2.62)$ & $1.22(0.97-1.53)$ \\
\hline Lag 2 & $0.68(0.38-1.21)$ & $0.89(0.66-1.20)$ & $0.37(0.16-0.85)^{*}$ & $0.91(0.70-1.19)$ \\
\hline 5 day mean & $1.13(0.47-2.76)$ & $1.04(0.58-1.86)$ & $0.09(0.02-0.37) *$ & $1.34(0.70-2.54)$ \\
\hline \multicolumn{5}{|l|}{ Black smoke } \\
\hline Lag 0 & $1.27(0.72-2.24)$ & $1.01(0.76-1.35)$ & $0.73(0.42-1.27)$ & $1.00(0.71-1.40)$ \\
\hline Lag 1 & $1.10(0.68-1.77)$ & $1.03(0.79-1.33)$ & $1.44(0.94-2.21)$ & $1.45(1.11-1.89)^{*}$ \\
\hline Lag 2 & $0.94(0.59-1.48)$ & $0.96(0.75-1.24)$ & $0.86(0.55-1.34)$ & $0.67(0.50-0.89)^{*}$ \\
\hline 5 day mean & $0.89(0.41-1.91)$ & $0.98(0.59-1.61)$ & $0.34(0.10-1.18)$ & $1.31(0.60-2.86)$ \\
\hline \multicolumn{5}{|l|}{ Sulphate } \\
\hline Lag 0 & $1.87(1.11-3.15)^{*}$ & $0.92(0.69-1.23)$ & $0.86(0.38-1.93)$ & $1.12(0.81-1.53)$ \\
\hline Lag 1 & $1.69(1.08-2.66)^{*}$ & $1.13(0.88-1.46)$ & $1.08(0.58-2.00)$ & $1.30(0.96-1.78)$ \\
\hline Lag 2 & $0.97(0.58-1.62)$ & $0.99(0.76-1.29)$ & $0.66(0.35-1.23)$ & $0.87(0.62-1.21)$ \\
\hline 5 day mean & $2.63(0.82-8.45)$ & $1.08(0.61-1.92)$ & $0.13(0.04-0.50)^{*}$ & $1.47(0.74-2.92)$ \\
\hline \multicolumn{5}{|c|}{ Sulphur dioxide } \\
\hline Lag 0 & $0.77(0.39-1.52)$ & $1.10(0.81-1.48)$ & $2.12(0.98-4.62)$ & $0.73(0.49-1.07)$ \\
\hline Lag 1 & $0.94(0.51-1.73)$ & $1.23(0.92-1.65)$ & $0.87(0.38-1.99)$ & $1.71(1.18-2.46)^{*}$ \\
\hline Lag 2 & $0.86(0.48-1.55)$ & $0.85(0.64-1.13)$ & $0.13(0.04-0.36)^{*}$ & $0.65(0.44-0.97)^{*}$ \\
\hline 5 day mean & $1.01(0.35-2.95)$ & $1.01(0.56-1.79)$ & $0.03(0.00-0.24)^{*}$ & $1.06(0.43-2.61)$ \\
\hline \multicolumn{5}{|c|}{ Nitrogen dioxide } \\
\hline Lag 0 & $0.85(0.57-1.26)$ & $0.95(0.79-1.15)$ & $0.71(0.48-1.04)$ & $1.05(0.87-1.27)$ \\
\hline Lag 1 & $1.00(0.69-1.49)$ & $0.95(0.80-1.12)$ & $1.12(0.76-1.65)$ & $1.00(0.82-1.21)$ \\
\hline Lag 2 & $0.81(0.56-1.17)^{\#}$ & $1.00(0.85-1.17)$ & $1.09(0.76-1.58)^{\#}$ & $0.88(0.73-1.06)$ \\
\hline 5 day mean & $0.44(0.18-1.08)$ & $0.98(0.63-1.51)$ & $0.54(0.25-1.20)$ & $0.90(0.50-1.62)$ \\
\hline
\end{tabular}

OR for an increase of $100 \mu \mathrm{g} \cdot \mathrm{m}^{-3}$ in particles with a $50 \%$ cut-off aerodynamic diameter of $10 \mu \mathrm{m}(\mathrm{PM} 10), 40 \mu \mathrm{g} \cdot \mathrm{m}^{-3}$ for black smoke, sulphur dioxide, nitrogen dioxide and $15 \mu \mathrm{g} \cdot \mathrm{m}^{-3}$ for sulphate. ${ }^{*}$ : OR significantly different from $1(\mathrm{p}<0.05)$; ${ }^{*}$ : difference in OR between urban and nonurban areas statistically significant $(\mathrm{p}<0.05) .>10 \%$ PEFmo: $>10 \%$ decrements in morning peak expiratory flow; URS: upper respiratory symptoms; Lag 0: current day concentration; Lag 1: previous day concentration; Lag 2: concentration of two days before; 5 day mean: mean concentration of current day and 4 previous days. 
The fact that no particle effects on evening PEF were observed is not in agreement with other studies that were mostly performed in children [3]. The same is true for the lack of association with LRS and bronchodilator use. The few panel studies that focused on adult symptomatic (mainly asthmatic) subjects also found that increased particle concentrations were most consistently associated with increased reporting of shortness of breath $[8,9]$, LRS and bronchodilator use [10]. The observed pattern of associations are therefore interpreted with caution, indicating at most a weak effect of outdoor air pollution.

Potential confounders that might bias the association between air pollution and respiratory health in time series studies are meteorological variables (mainly ambient temperature), respiratory infections and long term time trends. All associations were adjusted for ambient temperature and for nonlinear long term time trends in the prevalence of symptoms, bronchodilator use and PEF decrements. The adjustment for time trends was more detailed than in previous panel studies which either specified no time trend or a linear trend. The incidence of ILI in the general population, registered by a general practitioner sentinel system, was used to adjust for the potential confounding effect of respiratory infections. In previous panel studies, no adjustments for the potential confounding effect of respiratory infections were made. The authors report in a separate paper [26] that the ILI incidence in the general population was associated with respiratory health in selected panels.

The adults in this study were not selected with respect to smoking status. Although smoking is clearly a major determinant of respiratory health status, it was not likely to be a confounder in this study, as it is unlikely that changes in cigarette use are associated with corresponding changes in air pollution levels. However, smoking might be considered as an effect modifier, although it is unclear whether smokers are more or less susceptible to the effects of air pollution than nonsmokers. It has been reported that smokers are less responsive than nonsmokers due to altered lung function and an increase in mucus, both of which could influence dose in the different regions of the lung [31]. It has also been suggested that smokers are more responsive than nonsmokers: in a study reported by DusSELDORP et al. [32], separate analyses in a small group of smokers $(n=9)$ suggested a greater susceptibility of smokers to PM10 pollution. Since it seems unclear how passive smoking affects susceptibility to air pollution, smokers, exsmokers and nonsmokers were included in the present study.

It is unlikely that the low response rate to the screening questionnaire resulted in biased effect estimates. In time series studies subjects serve as their own controls thus effect estimates are valid for the selected panel. Only in the unlikely case that subjects that were more (or less) susceptible to air pollution were preferentially selected, could the effect estimates for the panel be different from those of the base study population.

In the present study, exposure assessment was based on fixed site ambient air concentrations measured at one location in both areas. It might be questioned whether exposure to air pollution was adequately characterized by only fixed site ambient air concentrations; if not, the resulting misclassification would probably result in a downward bias of the observed association between air pollution and health end-points. Compared with children, adults generally spend less time outdoors and, consequently, the amount of misclassification in exposure assessment might be larger. A number of recent studies in the Netherlands [33-35] have shown that the time series correlation between ambient and personal PM10 and especially PM2.5 is high. For 10-12 yr old children and 50-70 yr old adults, the median correlation coefficient between ambient and personal PM10 was 0.63 and 0.50, respectively, which shows that the amount of misclassification in adults was only slightly higher than for children.

Compared to other panel studies, a different approach was used to analyse PEF data, focusing not on decrements in population mean PEF but on the fraction of subjects that experienced substantial PEF decrements. In a reanalysis of data from seven panel studies of school children, symptomatic and nonsymptomatic children, HoEk et al. [29] compared the two approaches and demonstrated that an increase of $100 \mu \mathrm{g} \cdot \mathrm{m}^{-3}$ of the same day PM10 concentration was associated with a decrement in population mean evening PEF of $0.7 \%$. The corresponding OR for the prevalence of $>10 \%$ and $>20 \%$ decrements were 1.31 and 1.41, respectively. Morning PEF data were not available in all studies and were therefore not included in the reanalysis [29]. In the current panels of symptomatic adults from urban areas, the OR for the association between an increase of $100 \mu \mathrm{g} \cdot \mathrm{m}^{-3}$ in same day PM10 concentration and the prevalence of $>10 \%$ and $>20 \%$ decrements in evening PEF were 1.05 and 0.71 , respectively (both nonsignificant). For morning PEF OR of 0.95 (nonsignificant) and 2.41 (95\% confidence interval: $1.22-4.78)$ were found for $>10 \%$ and $>20 \%$ decrements, respectively. A possible explanation for the observed association with morning PEF, rather than with evening PEF might be that morning PEF is less affected by medication used during the day. Since morning PEF is more determined by allergen exposure at night [36] than is evening PEF, pollution-allergen interaction might be another explanation. Controlled human exposure studies have indicated that exposure to gaseous air pollutants may increase the airway responsiveness of asthmatics to inhaled allergen such as house dust mites [37, 38]. Recently, it has been reported that in a murine model of allergic asthma, particulates were able to enhance mite-induced airway responsiveness [39], suggesting that this might be a reasonable explanation. To the authors' knowledge, no controlled human exposure studies investigating pollution-allergen interactions have been performed with particulate air pollution. Allergic reactions to indoor allergens include irritation of the upper respiratory tract, which might also explain the observed association between particles and URS.

No association between indicators of air pollution and respiratory health was observed in the panels of nonsymptomatic adults. To our knowledge, only one other panel study [12] has been performed on adults not selected for chronic respiratory symptoms. In that study, sulphate concentration was associated with LRS, while coefficient of haze (a more general measure of particulates) was not. Neither sulphates nor coefficient of haze were associated with URS. $\mathrm{SO}_{2}$ and $\mathrm{NO}_{2}$ were not associated with any respiratory health outcome. The results of the study by Ostro et al. [12] agree with the results of the present study in nonsymptomatic adults, although no association with LRS was observed in the present study. 
Associations between particulate air pollution and respiratory health indicators were observed in symptomatic adults from the urban areas, but not from the nonurban areas. However, especially for sulphate the $20 \%$ morning PEF effect estimates in the nonurban areas were similar. In addition, confidence intervals for the urban and nonurban areas overlapped widely. If the observed difference is interpreted as a true difference between the urban and nonurban areas, it might be explained by the higher asthma medication use in the nonurban symptomatic panels, as it has been suggested that medication use attenuates the association between air pollution and respiratory health $[13,40]$. Bronchodilator use was not associated with particle concentrations and the health outcomes for which particle effects were observed in the urban panels (morning PEF and URS) are probably least affected by asthma medication use. Despite this, it cannot be ruled out that differences in asthma medication use are responsible for the observed differences in response between urban and nonurban panels. The differences in response between urban and nonurban symptomatic panels is not explained by differences in the fraction of atopic subjects (49\% in urban and $46 \%$ in nonurban areas). Exclusion of the data from the first winter from the calculation of a combined estimate for the urban panel, resulted in effect estimates that were similar to those presented. Most estimates were even slightly larger when the first winter was excluded. Thus, the difference is not due to the fact that in the first winter, with relatively high particle and $\mathrm{SO}_{2}$ concentrations, only subjects in the urban area were studied. Another, more speculative explanation might be that urban particles are more toxic, $\left(\right.$ per $\left.\mu \mathrm{g} \cdot \mathrm{m}^{-3}\right)$, than the nonurban particles. This might be due to the larger number of ultrafine particles $(<0.1 \mu \mathrm{m})$ in urban air, or to a more toxic chemical composition of urban particles.

Transient decrements of forced vital capacity (FVC) and forced expiratory volume in one second (FEV1) of 20\% have been considered as the border between moderate and severe response [41]. The effect estimates observed in the current study indicate that in symptomatic adults from urban areas, an increase in 5-day mean BS concentration of $40 \mu \mathrm{g} \cdot \mathrm{m}^{-3}$ is associated with a four-fold increase in the number of subjects with a response that could be characterized as severe. Although the prevalence of $>20 \%$ decrements in morning PEF was low $(1.5 \%)$, this refers to a substantial 60 events per 1,000 person-days that are attributable to elevated $\mathrm{BS}$ concentrations.

The association between $\mathrm{SO}_{2}$ and morning PEF that was observed in symptomatic, urban panels was found at very low $\mathrm{SO}_{2}$ concentrations, with medians of 25,11 and 6 $\mu \mathrm{g} \cdot \mathrm{m}^{-3}$ during the three winters, respectively, and maximum concentrations never higher than $61 \mu \mathrm{g} \cdot \mathrm{m}^{-3}$. Although within $24 \mathrm{~h}$ time periods, higher short-term concentrations are observed, direct $\mathrm{SO}_{2}$ effects seem unlikely at these levels [1]. The authors think that $\mathrm{SO}_{2}$ in these circumstances serves as an indicator for a more complex mixture which contains the actual responsible components. BS was more consistently associated with the prevalence of $>20 \%$ decrements in morning PEF and URS than PM10 and sulphate. BS can be considered as an indicator of fine black particles (elemental carbon) emitted by diesel engines which is generally found in the fine to ultrafine particle fraction.
In conclusion, weak particle effects were observed in symptomatic adults from urban areas, but not from nonurban areas. However, the differences in effect-estimates between urban and nonurban symptomatic panels were small and nonsignificant. In nonsymptomatic adults from both urban and nonurban areas no particle effects were observed.

\section{References}

1. World Health Organisation. Air quality guidelines for Europe. WHO regional publications. European series no 23. Copenhagen, 1987.

2. Chow J. Measurement methods to determine compliance with ambient air quality standards for suspended particles. J Air Waste Manage Assoc 1995; 45: 320-382.

3. Dockery DW, Pope CA III. Acute respiratory effects of particulate air pollution. Annu Rev Public Health 1994; 15: $107-132$.

4. Brunekreef B, Dockery DW, Krzyzanowski M. Epidemiological studies on short-term effects of low levels of major ambient air pollution components. Environ Health Perspect 1995; 103 (Suppl. 2): 3-13.

5. Roemer W, Hoek G, Brunekreef B. Effect of ambient winter air pollution on respiratory health of children with chronic respiratory symptoms. Am Rev Respir Dis 1993; 147: 118-124.

6. Hoek G, Brunekreef B. Acute effects of a winter air pollution episode on pulmonary function and respiratory symptoms in children. Arch Environ Health 1993; 48: 328-335.

7. Hoek G, Brunekreef B. Effects of low level winter air pollution concentrations on respiratory health of Dutch children. Environ Res 1994; 64: 136-150.

8. Forsberg B, Stjernberg N, Falk M, Lundbaeck B, Wall S. Air pollution levels, meteorological conditions and asthma symptoms. Eur Respir J 1993; 6: 1109-1115.

9. Dusseldorp A, Kruize H, Brunekreef B, Hofschreuder P, Meer G de, van Oudvorst AB. Acute effects of PM10 and airborne iron on respiratory health: a panel study among adults living near a steel industry in the Netherlands. $\mathrm{Am} \mathrm{J}$ Respir Crit Care Med 1995; 152: 1932-1939.

10. Ostro BD, Lipsett MJ, Wiener MB, Selner JC. Asthmatic responses to airborne acid aerosols. Am J Public Health 1991; 81: 694-702.

11. Peters A, Goldstein IF, Beyer U, et al. Acute health effects of exposure to high levels of air pollution in Eastern Europe. Am J Epidemiol 1996; 144: 570-581.

12. Ostro BD, Lipsett MJ, Mann JK, Krupnick A, Harrington W. Air pollution and respiratory morbidity among adults in southern California. Am J Epidemiol 1993; 137: 691-700.

13. Pope CA III, Dockery DW, Spengler JD, Raizenne ME. Respiratory health and PM10 pollution: a daily time series analysis. Am Rev Respir Dis 1991; 144: 668-674.

14. Pope CA III, Dockery DW. Acute health effects of PM10 pollution on symptomatic and asymptomatic children. $\mathrm{Am}$ Rev Respir Dis 1992; 145: 1123-1128.

15. Pope CA III, Kanner RE. Acute effects of PM10 pollution on pulmonary function of smokers with mild to moderate chronic obstructive pulmonary disease. Am Rev Respir Dis 1993; 147 1336-1340.

16. Schwartz J. What are people dying of on high air pollution days? Env Research 1994; 64: 26-35.

17. van der Zee SC, Hoek G, Boezen HM, Schouten JP, Wijnen JH van, Brunekreef B. Acute effects of urban air pollution on respiratory health of children with and 
without chronic respiratory symptoms. Occup Environ Med 2000; 56: 802-813.

18. Burney PGJ, Luczynska C, Chinn S, Jarvis D. European study protocols: the European Community Respiratory Health Survey. Eur Respir J 1994; 7: 954-960.

19. van der Zee SC, Hoek G, Harssema H, Brunekreef B. Characterization of particulate air pollution in urban and non-urban areas in the Netherlands. Atmos Environ 1998; 32: 3717-3729.

20. Liu BYH, Pui DYH. Aerosol sampling inlets and inhalable particles. Atmos Environ 1981; 15: 589-600.

21. Hoek G, Brunekreef B. Acute effects of a winter air pollution episode on pulmonary function and respiratory symptoms of children. Arch Environ Health 1993; 48: 328-335.

22. Organization for Economic Cooperation and Development, OECD. Methods of measuring air pollution. Report of the working group on methods of measuring air pollution and survey techniques. OECD Paris, France, 1964.

23. Koutrakis P, Wolfson JM, Spengler JD. An improved method for measuring aerosol strong acidity: results from a nine-month study in St Louis, Missouri and Kingston, Tennessee. Atmos Environ 1988; 22: 157-162.

24. Hoek G, Mennen MG, Allen GA, Hofschreuder P, van der Meulen. Concentrations of acidic air pollutants in the Netherlands. Atmos Environ 1996; 30: 3141-3150.

25. Elskamp HJ. National Air Quality Monitoring Network. Technical description. National Institute of Public Health and Environmental Protection. Report no. 228702017. Bilthoven, the Netherlands, 1989.

26. van der Zee SC, Hoek G, Brunekreef B. Incidence of influenza-like illness, measured by a GP sentinel system, is associated with day-to-day variations in respiratory health in panel. Am J Epidemiol 1999; (In press).

27. Roemer W, Hoek G, Brunekreef B, et al. Effect of shortterm changes in urban air pollution on the respiratory health of children with chronic respiratory symptoms The PEACE project: Introduction. Eur Respir Rev 1998; 8: 4-11.

28. Roemer W, Hoek G, Brunekreef B, et al. for the PEACE project. Daily variations in air pollution and respiratory health in a multi-centre study: the PEACE project. Eur Respir J 1998; 12: 1354-1361.

29. Hoek G, Dockery DW, Pope CA, Neas L, Roemer W, Brunekreef B. Association between PM10 and decrements in peak expiratory flow rates in children: a reanalysis of data from five panel studies. Eur Respir $J$ 1998; 11: 1307-1311.

30. SAS Institute. SAS/ETS User's guide, version 6. SAS Institute Inc., Cary, NC, USA, 1988.

31. Lebowitz MD. Epidemiological studies of the respiratory effects of air pollution. Eur Respir J 1996; 9: 1029-1054.

32. Dusseldorp A, Kruize H, Brunekreef B, Hofschreuder P, de Meer G, van Oudvorst AB. Acute effects of PM10 and airborne iron in respiratory health: a panel study among adults living near a steel industry in the Netherlands. $\mathrm{Am} \mathrm{J}$ Respir Crit Care Med 1995; 152: 1932-1939.

33. Janssen NAH, Hoek G, Harssema H, Brunekreef B. Childhood exposure to PM10: a relation between personal, classroom, and outdoor concentrations. Occup Environ Med 1997; 54: 888-894.

34. Janssen NAH, Hoek G, Harssema H, Brunekreef B. Personal exposure to fine particles in children correlates closely with ambient fine particles. Arch Environ Health 1999; (In press).

35. Janssen NAH, Hoek G, Brunekreef B, Harssema H, Mensink I, Zuidhof A. Personal sampling of particles in adults: relation among personal, indoor, and outdoor air concentrations. Am J Epidemiol 1998; 147: 537-547.

36. Meijer GG, Postma DS, van der Heide S, et al. Exogenous stimuli and circadian peak expiratory flow variation in allergic asthmatic children. Am J Respir Crit Care Med 1996; 153: 237-242.

37. Rusznak C, Devalia JL, Davies RJ. The airway response of asthmatic subjects to inhaled allergen after exposure to pollutants. Thorax 1996; 51: 1105-1118.

38. Devalia JL, Rusznak C, Herdman MJ, Trigg CJ, Tarraf H, Davies RJ. Effect of nitrogen dioxide and sulphur dioxide on the airway response of mild asthmatic patients to allergen inhalation. Lancet 1994; 344: 1668-1671.

39. Walters DM, Wills-Kirp M. Particulates enhance house dust mite-induced airway hyperresponsiveness in a murine model of allergic asthma. Am J Respir Crit Care Med 1998; 157: A152.

40. Silverman F, Hosein HR, Corey P, Holton S, Tarlo SM. Effects of particulate matter exposure and medication use on asthmatics. Arch Environ Health 1992; 46: 51-56.

41. World Health Organisation. Acute effects on health of smog episodes. WHO regional publications, European series no. 43. Geneva, Switzerland, 1992. 